\title{
A TEST APPARATUS AND FACILITY' TO IDENTIFY THE ROTORDYNAMIC COEFFICIENTS OF HIGH-SPEED HYDROSTATIC BEARINGS
}

\author{
Dara Childs and Keith Hale \\ Texas A\&M University \\ College Station, Texas
}

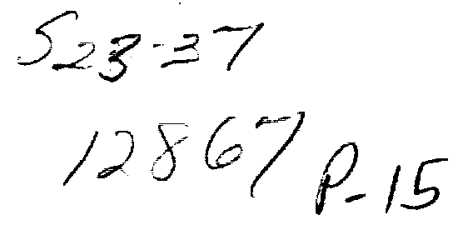

Abstract

A facility and apparalus are described which determine stiffness, damping, and added-mass rotordynamic coefficients plus steady-state operating characteristics of high speed hydrostatic journal bearings. The apparatus has a current top speed of $29800 \mathrm{rpm}$ with a bearing diameter of $7.62 \mathrm{~cm}\left(3 \mathrm{in}\right.$.). Purified warm water, $55^{\circ} \mathrm{C}\left(130^{\circ} \mathrm{F}\right)$, is used as a test fluid to achieve elevated Reynolds numbers during operation. The test-fluid pump yields a bearing maximum inlet pressure of $6.9 \mathrm{Mpa}$ (1000 psi). Static load on the bearing is independently controlled and measured. Orthogonally mounted external shakers are used to excite the test stator in the direction of, and perpendicular to, the static load. The apparatus can independently calculate all rotordynamic coefficients at a given operating condition.

\section{Introduction}

Experience with the SSME (Space Shuttle Main Engine) has demonstrated definite limits for the successful operation of ball bearings in liquid oxygen (LOX). Currently, bearings in the HPOTP (High Pressure Oxygen Turbopump) of the SSME experience accelerated wear at full power level. The balls in these bearings simply get smaller, rapidly. The problem has proven largely intractable. As a result, hydrostatic bearings have been proposed for many new turbopump applications because of their long lifetime, low friction factors, low wear, and their ability 10 use low-viscosity lubricants. For cryogenic applications, the bearings will be pressurized from pump-discharge flow. At zero speeds the bearings will be flooded but unpressurized. Rubbing will be experienced at start up and shut down as investigated by Scharrer et al. (1992 a, 1992 b). The present research concerns steady-state fully pressurized bearing operation.

The lest apparatus and facility described here is used to develop experimentally validated tools to predict steady-state hydrostatic bearing operational data (resistance torque, static load, flowrate, temperature and pressure distributions, etc.) and rotordynamic coefficients for vibration analysis. By rotordynamic coefficients, we refer to the stiffness $K$, damping $C$, and added-mass $M$ coefficients which are used in the following linearized force-displacement model for bearings

$$
-\left\{\begin{array}{l}
f_{b x} \\
f_{b y}
\end{array}\right\}=\left[\begin{array}{ll}
K_{x x} & K_{x y} \\
K_{y x} & K_{y y}
\end{array}\right]\left\{\begin{array}{l}
\Delta x \\
\Delta y
\end{array}\right\}+\left[\begin{array}{ll}
C_{x x} & C_{x y} \\
C_{y x} & C_{y y}
\end{array}\right]\left\{\begin{array}{l}
\Delta x \\
\Delta y
\end{array}\right\}+\left[\begin{array}{ll}
M_{x x} & M_{x y} \\
M_{y x} & M_{y y}
\end{array}\right]\left\{\begin{array}{l}
\Delta x \\
\Delta y
\end{array}\right\}
$$

Here, $(\Delta x, \Delta y)$ define the motion of the bearing rotor relative to its stator, and $\left(f_{b x}, f_{b y}\right)$ are the components of the fluid film reaction force acting on the rotor. Identification of the rotordynamic coefficients of Eq.(1) is a central objective of this research project.

This paper describes the test-facility design requirements necessary to identify the rotordynamic coefficients

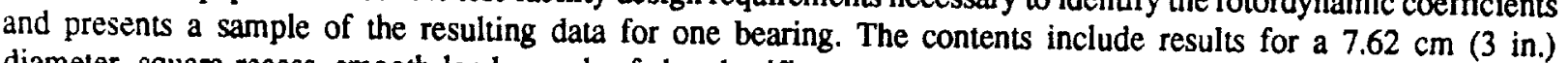
diameter, square-recess, smooth-land, annular-fed and orifice-compensated hydrostatic journal bearing with an L/D ratio of 1 and a $C / R$ ratio of 0.003 . The design requirements and analysis techniques for determining the steady-state operational data are detailed thoroughly by Kurtin, et al.(1991) and will not be repeated here. Subsequent publications will provide test results for hydrostatic bearings with assorted recess shapes, distinct land patterns and roughness, varied area ratios, and tangential-injection against rotation.

\footnotetext{
'The research reported here was supponed in part by Rocketdyne, Division of Rockwell International, under Contract No. R94QBA89-032182, NASA through the Texas A\&M University Center for Space Power, Contract No. NAGW-1194, and The State of Texas Advanced Technology Research Program
under Contract No. 4449 .
} 


\section{Apparatus and Facility -- An Introduction and Overview}

The Hydrostatic Bearing Test Stand illustrated in Figure 1 consists of the following major components. A base, fabricated from welded steel plates, supports the test section, gearbox, and drive motor. In the test section, two

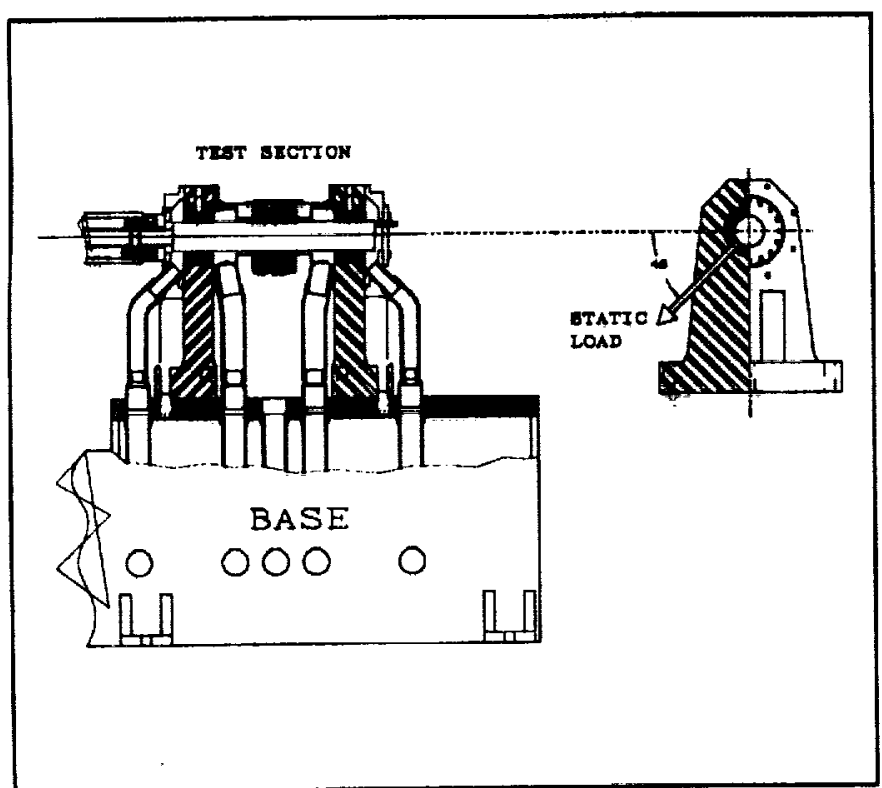

Figure 1 Bearing-test-apparatus layout stainless steel pedestals spaced about $38 \mathrm{~cm}(15$ inches) apart support a $7.62 \mathrm{~cm}(3 \mathrm{in}$.) diameter stainless steel high-speed rotor. The rotor is driven by a $93.2 \mathrm{Kw}$ (125 HP) variable-speed electric motor through a 7:1 ratio speed-increasing gearbox via a disc-type coupling. The test-bearing stator supports itself on the rotor at a position midway between the support pedestals. A pneumatic cylinder provides a fixed-direction side load to the bearing.

Two orthogonally mounted hydraulic shakers are attached to the stator through isolation stingers as illustrated in Figure 2. The shakers provide excitation parallel and perpendicular to the static side load along the $X$ and $Y$ directions, respectively. Each shaker can excite the stator with measured dynamic loads to $4450 \mathrm{~N}(1000 \mathrm{Lb})$ at frequencies to $1000 \mathrm{hz}$. The stingers were designed following guidelines by Mitchell and Elliott (1984). The static and dynamic loading arrangement of Figure 1 and Figure 2 is most closely related to that of Kanki and Kawakami (1984) who use orthogonal static loads from pneumatic cylinders in series with electromechanical shakers to excite the stator in a liquid-seal test rig. Glienicke (1966-67) is normally credited with the initial development of this rig type. Tonnesen and Hansen (1982) used this type of hydrostatic support bearings setup in static tests to investigate temperature effects of hydrodynamic bearings.

Preloaded axial cables arranged in an opposing trihedral configuration (Figure 3) constrain the shaft during static loading and dynamic excitation. A pitch mode instability of the stator with rotor onset speed around 17,000 rpm was also eliminated by these cables. This pitch restraint concept came from Nordmann and Massman (1984), who used a similar design on a liquid-seal test rig. The pitchrestraint cables have an additional advantage in insuring that the stator remains parallel to the rolor during excitation. Alternatively, they have been used to deliberately misalign a test bearing during excitation.

Retuming to Figure 2, note that accelerometers are provided to measure the stator acceleration in the $X$ and $Y$ directions. Although not illustrated in Figure 2, the relative deflections $\Delta x(t), \Delta y(t)$ between the bearing rotor and stator are also measured with high-resolution eddy-current transducers. In summary, dynamic measurements at the bearing for rotordynamic coefficient identification include the dynamic excitation forces, the stator acceleration, and the relative rotor-stator deflections in the $X$ and $Y$ directions.

Purified water at $55^{\circ} \mathrm{C}\left(130^{\circ} \mathrm{F}\right)$ is supplied to the

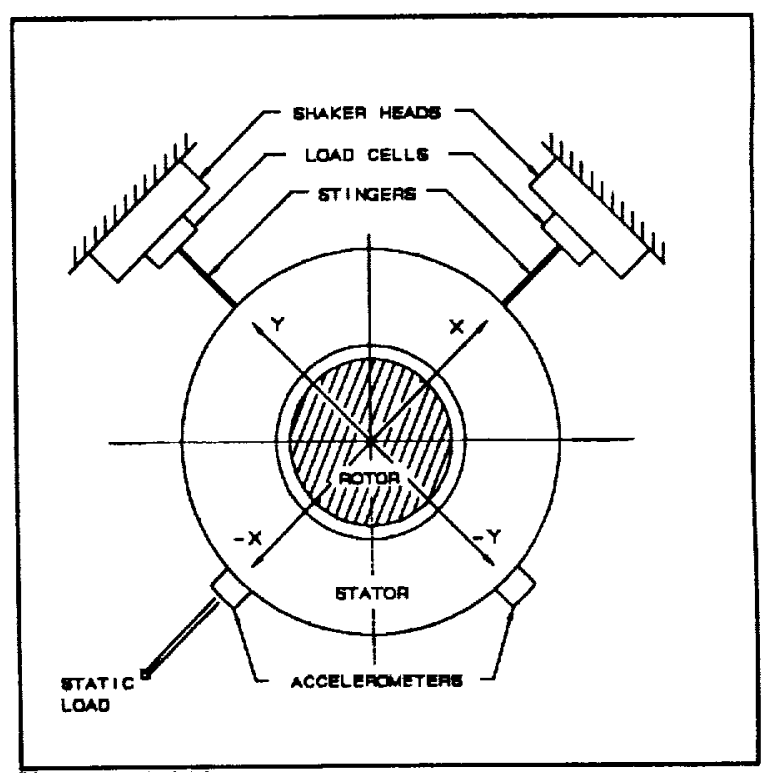

Figure 2 End view of a test bearing 
support and test bearings via a centrifugal pump with pressure and flow rate capacities of $6895 \mathrm{Kpa} \mathrm{(1100} \mathrm{psi)} \mathrm{and}$ 303 liters/min $(80 \mathrm{gpm})$, respectively. The main pump supplies the water to the lest section through 10 -micron absolute filters. The test-bearing flowrate is monitored by a turbine flowmeter and adjusted by a remotely-controlled valve. Nitrogen-backed accumulators provide a pressurized bearing coastdown in the event of a main pump failure. The water is elevated to test temperature by heat input from the main pump and test section. Two PID-controlled valves mix cooler water from a large 15,000 liter (4000 gallon) reservoir to maintain a constant fluid temperature at the test bearing inlet. The equipment is protected by an extensive logic-controlled monitoring and fault detection network capable of partially or totally unassisted safe shutdowns.

The test apparatus has been designed to facilitate rapid testing of multiple bearing configurations. The coupling design of Figure 1 allows rapid removal of a test rotor, followed by speedy replacement of a test bearing. A complcte bearing test is accomplished in one weck, including bearing and rotor installation, calibration, testing, and a computer-generated test report. Actual testing is computer driven and takes on the order of one-half day.

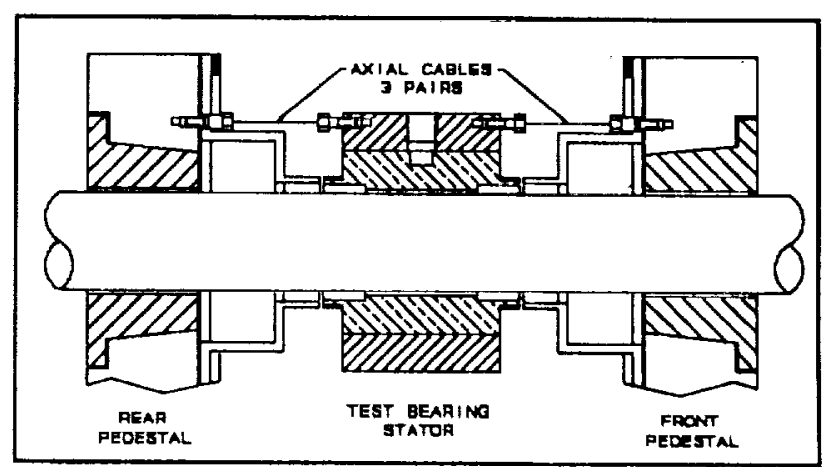

Figure 3 Side vicw of a lest bearing showing axial tensioning cables

\section{Rotordynamic-Coefficient Identification}

The preceding section introduced the test apparatus and facility and explained the dynamic measurements taken at the bearing. The present section explains how the measurements are used to identify the rotordynamic coefficients.

The equations of motion for the stator mass $M$, of Figure 2 can be written

$$
M_{s}\left\{\begin{array}{l}
\ddot{x}_{s} \\
\ddot{y}_{s}
\end{array}\right\}=\left\{\begin{array}{l}
f_{x} \\
f_{y}
\end{array}\right\}+\left\{\begin{array}{l}
f_{x b} \\
f_{y b}
\end{array}\right\}
$$

Where $x_{s}, y_{y}$ are the (measured) components of the stator's acceleration, $f_{x}, f_{y}$ are the (measured) components of the input excitation forces, and $f_{x b}, f_{y b}$ are the bearing-reaction force components. The $x$ and $y$ subscripts in these equations identify the $X$ and $Y$ directions of Figure 2. Substituting from Eq.(1) and rearranging Eq.(2) gives

$$
\left\{\begin{array}{l}
f_{x}-M_{s} \ddot{x}_{s} \\
f_{y}-M_{s} \ddot{y}_{s}
\end{array}\right\}=\left[\begin{array}{ll}
K_{x x} & K_{x y} \\
K_{y x} & K_{y y}
\end{array}\right]\left\{\begin{array}{l}
\Delta x \\
\Delta y
\end{array}\right\}+\left[\begin{array}{ll}
C_{x x} & C_{x y} \\
C_{y x} & C_{y y}
\end{array}\right]\left\{\begin{array}{l}
\Delta \dot{x} \\
\Delta \dot{y}
\end{array}\right\}+\left[\begin{array}{ll}
M_{x x} & M_{x y} \\
M_{y x} & M_{y y}
\end{array}\right]\left\{\begin{array}{l}
\Delta \ddot{x} \\
\Delta \ddot{y}
\end{array}\right\}
$$

Since the mass $M$, is known, the left-hand vector of Eq.(3) is a known function of time. On the right-hand side, $\Delta x(t)$ and $\Delta y(t)$ are measured functions of time. The rotordynamic coefficients are determined in the frequency domain via the Fourier Transform $\mathscr{S}$ which yields,

$$
\left\{\begin{array}{l}
F_{x}-M_{y} A_{x} \\
F_{y}-M_{y} A_{y}
\end{array}\right\}=\left[\begin{array}{ll}
H_{x x} & H_{x y} \\
H_{y x} & H_{y y}
\end{array}\right]\left\{\begin{array}{l}
D_{x} \\
D_{y}
\end{array}\right\}
$$


where

$$
F_{k}=\mathscr{\rho}\left(f_{k}\right), \quad A_{k}=\Im\left(k_{g}\right), \quad D_{k}=\Im(\Delta k)
$$

The elements of the frequency-response function (FRF) $\boldsymbol{H}$ are related to the coefficients defined in Eq. (3) by,

$$
\begin{aligned}
& H_{x x}=\left(K_{x x}-\omega^{2} M_{x x}\right)+j\left(\omega C_{x x}\right) \\
& H_{x y}=\left(K_{x y}-\omega^{2} M_{x y}\right)+j\left(\omega C_{x y}\right) \\
& H_{y x}=\left(K_{y x}-\omega^{2} M_{y x}\right)+j\left(\omega C_{y x}\right) \\
& H_{y y}=\left(K_{y y}-\omega^{2} M_{y y}\right)+j\left(\omega C_{y y}\right)
\end{aligned}
$$

where $\omega$ is the excitation frequency and $j=\sqrt{-1}$.

However, Eq.(4) only provides two complex equations for the four unknown $\boldsymbol{H}_{i}$ 's. To get four independent equations, two independent orthogonal dynamic loads are applied to the stator by alternately exciting along the $\mathrm{X}$ and $Y$ directions of Figure 2. Each of these "pseudo-random" dynamic loads contains 41 sinusoids. The superposition of these sinusoids is optimized to provide a composite loading that has a high $\boldsymbol{F}$ spectral-line energy to crest-factor ratio. The loadings are periodic and have energy only at $10 \mathrm{~Hz}$ frequency increments in the range from 40 to 440 $\mathrm{Hz}$. The two independent loadings result in the four complex equations,

$$
\left[\begin{array}{ll}
F_{x x}-M_{s} A_{x x} & F_{x y}-M_{s} A_{x y} \\
F_{y x}-M_{s} A_{y x} & F_{y y}-M_{s} A_{y y}
\end{array}\right]=\left[\begin{array}{ll}
H_{x x} & H_{x y} \\
H_{y x} & H_{y y}
\end{array}\right]\left[\begin{array}{ll}
D_{x x} & D_{x y} \\
D_{y x} & D_{y y}
\end{array}\right],
$$

where the subscripts $i j$ of the force and displacement matrices correspond to response in the $i$ direction due to dynamic loading in the $j$ direction (Figure 2). Appendix A provides a complete discussion of the power-spectral density method used to calculate the $\mathbf{H}_{\mathbf{v}}$ functions.

\section{Steady-State Operating Conditions}

The test equipment varies the test bearing steady-state operating conditions by independently controlling the following four parameters:

1) Rotor speed,

2) Test fluid supply pressure,

3) Static bearing load, and

4) Test fluid supply temperature.

The normal operating-condition test matrix includes three running speeds from 10,000 to $25,000 \mathrm{rpm}$, three supply pressures from 4 to $7 \mathrm{Mpa}$ (600 to $1000 \mathrm{psi}$ ), and six eccentricity ratios (determined by the static load) ranging from concentric to 0.5 . Tests are conducted at a single temperature, usually $55^{\circ} \mathrm{C}\left(130^{\circ} \mathrm{F}\right)$; however, the test apparatus has been operated to $29,800 \mathrm{rm}$ at $71^{\circ} \mathrm{C}\left(160^{\circ} \mathrm{F}\right)$.

Reynolds-numbers estimates for the test seal at $28,000 \mathrm{rpm}, \mathrm{C} / \mathrm{R}=.0033$, with $160^{\circ} \mathrm{F}$ water is

$$
\begin{aligned}
& \mathbf{R}_{\theta}=R_{\omega} C_{r} \rho / \mu=37,400, \quad \mathbf{R}_{z}=2 W C_{r} \rho / \mu=20,600 \\
& R=\sqrt{R_{t}^{2}+R^{2}}=42,700, \quad \quad R / R_{z}=1.82
\end{aligned}
$$


For comparison, a typical liquid-oxygen turbopump bearing would have

$$
\mathbf{R}_{\theta}=91,300, \quad \mathbf{R}_{z}=113,200, \quad \mathbf{R}=145,400, \quad \mathbf{R}_{\theta} / \mathbf{R}_{z}=.81,
$$

and a typical hydrogen bcaring would give

$$
\mathbf{R}_{0}=121,300, \quad \mathbf{R}_{\tau}=366,600, \quad \mathbf{R}=386,200, \quad \mathbf{R}_{d} / \mathbf{R}_{\tau}=.33 .
$$

P for the LOX and $\mathrm{H}_{2}$ bearings is seen to be about 3.5 and 9 times higher, respectively, than corresponding water values.

\section{Test Bearing}

As reviewed earlier, the test apparatus is used to identify rotordynamic coefficients of hydrostatic bearings with a variety of geometric configurations. The results presented here are for the 5recess bearing of Figure 4, whose physical properties and dimensions are described in table 1. The bearing area ratio is the recess area divided by the total bearing area. The bearing's outer and inner shells are made, respectively, from aluminum and bronze. Shallow recess depths are typically required in cryogenic bearings to avoid "water hammer" by minimizing the recess volume. Because of the small depths, and the requirement of a smooth recess surface, recesses were
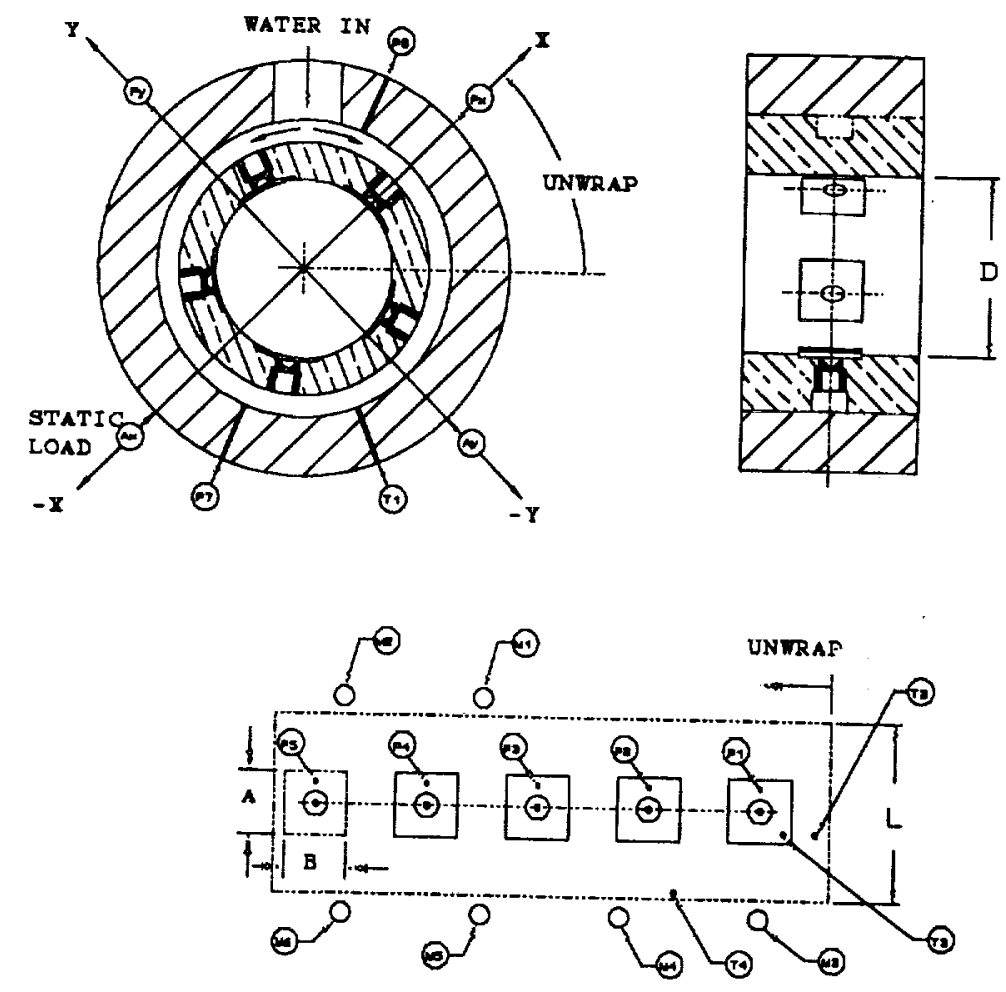

Figure 4 Typical 5-Recess Hydrostatic Bearing manufactured by an Electrical Discharge Machining (EDM) process.

Hot water enters as illustrated at the top left-hand element of figure 4, circulates through a $360^{\circ}$ annulus and enters the recesses through orifices. Close-coupled, strain-gauge pressure transducers measure the static and dynamic pressures within each bearing recess. The unwrapped bearing view at the bottom of figure 4 and the end view at the left-hand side summarize the measurements made on a test bearing, with $Q, \Theta .(\mathcal{O}, \mathcal{D}$, and (ब) denoting, respectively; relative motion, input force, pressures, temperatures, and accelerations. Table 2 documents the
measurement mnemonics of figure 4 .

Figure 5 provides a detailed view of the orifice and recess cross section. The apparatus design provides access and easy replacement of each orifice. Observe that there is a $90^{\circ}$ expansion flow cone for a transition section 
Table 1. Test-bearing physical parameters (Refer to figure 4 for dimension definitions.)

$\begin{array}{ll}\text { Mass } & 11.34 \mathrm{~kg}(25 \mathrm{lb}) \\ \text { Diameter (O.D.) } & 76.441 \mathrm{~mm}(3.0095 \mathrm{in}) \\ \text { Diameter (I.D.) } & 76.200 \mathrm{~mm}(3.0000 \mathrm{in}) \\ \text { Radial Clearance } & 0.12 \mathrm{~mm}(0.0048 \mathrm{in}) \\ \text { Length (L) } & 76.2 \mathrm{~mm}(3 \mathrm{in}) \\ \text { No. of Recesses } & 5 \\ \text { Recess dimension A } & 27.0 \mathrm{~mm}(1.064 \mathrm{in}) \\ \text { Recess dimension B } & 27.0 \mathrm{~mm}(1.064 \mathrm{in}) \\ \text { Recess Volume } & 0.184996 \mathrm{E}-6 \mathrm{~m}^{3}\left(0.0112891 \mathrm{in}^{3}\right) \\ \text { Area Ratio } & 0.2 \\ \text { Recess depth } & 0.259 \mathrm{~mm}(0.010 \mathrm{in}) \\ \text { Orifice Diameter } & 2.49 \mathrm{~mm}(0.098 \mathrm{in}) \\ \text { Orifice Supply Line Volume } & 0.128994 \mathrm{E}-6 \mathrm{~m}^{3}\left(0.00787173 \mathrm{in}^{3}\right) \\ \text { Land Roughness (peak-peak) } & 0.330 \mu \mathrm{m}(13 \mu \mathrm{in})\end{array}$

Table 2. Mnemonic definitions for measurements in ligure 4.

\begin{tabular}{|c|c|c|}
\hline MEASUREMENT & MNEMONIC & LOCATION/DIRECTION \\
\hline \multirow[t]{6}{*}{ RELATIVE MOTION } & M1 & FRONT / X- \\
\hline & M2 & FRONT / Y- \\
\hline & M3 & $\operatorname{REAR} / \mathrm{X}$ \\
\hline & M4 & REAR / Y \\
\hline & M5 & REAR / X- \\
\hline & M6 & REAR / Y- \\
\hline \multirow[t]{7}{*}{ PRESSURE } & P1 & RECESS 1 \\
\hline & $\mathrm{P} 2$ & RECESS 2 \\
\hline & P3 & RECESS 3 \\
\hline & $\mathrm{P} 4$ & RECESS 4 \\
\hline & P5 & RECESS 5 \\
\hline & P6 & INLET ANNULUS \\
\hline & P7 & BACKSIDE ANNULUS \\
\hline \multirow[t]{4}{*}{ TEMPERATURE } & $\mathrm{T} 1$ & ANNULUS \\
\hline & $\mathrm{T} 2$ & LAND AT RECESSES \\
\hline & $\mathrm{T3}$ & RECESS 1 \\
\hline & T4 & LAND AT EXIT \\
\hline \multirow[t]{2}{*}{ ACCELERATION } & $\mathrm{Ax}$ & CENTER / X \\
\hline & Ay & CENTER / Y \\
\hline \multirow[t]{2}{*}{ FORCE } & $F x$ & CENTER / X \\
\hline & Fy & CENTER / Y \\
\hline
\end{tabular}




\section{Representative Dynamic Test Data}

Figure 6 illustrates the real and imaginary parts of $\mathrm{H}_{\mathrm{x}}$ and $\mathrm{H}_{\mathrm{xy}}$ for a test case defined by zero eccentricity, $24600 \mathrm{pm}$, and $6.9 \mathrm{Mpa}$ (1000 psi) supply pressure. The dots in the figure are calculated transferfunction values resulting from an average (in the frequency domain) of 32 separate excitations. Note the discrepant data points at running speed $(410 \mathrm{~Hz})$. Poor FRF accuracy can result at this frequency because rotor imbalance and runout can combine with the stator excited motion to result in very small relative displacements. This problem is fixable by phase locking the stator input excitation to the rotor angular position, but this fix has not been implemented. Hence, data points at or near the nunning speed were dropped in obtaining the curve-fitted lines shown in figure 6.

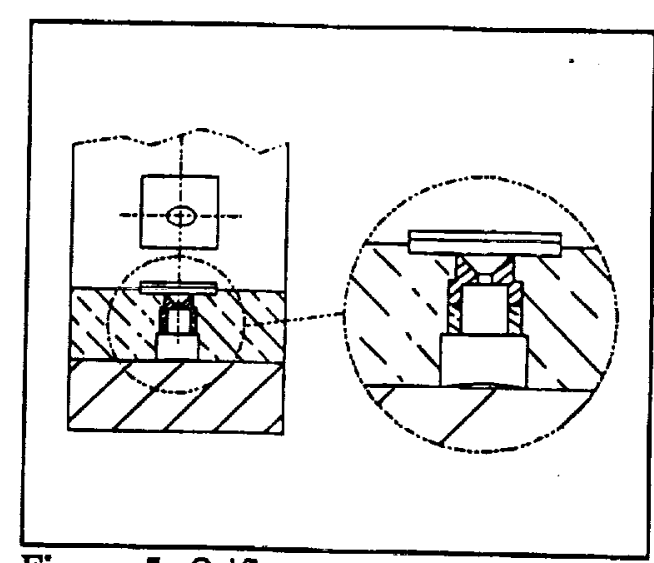

Figure 5 Orifice and recess detail
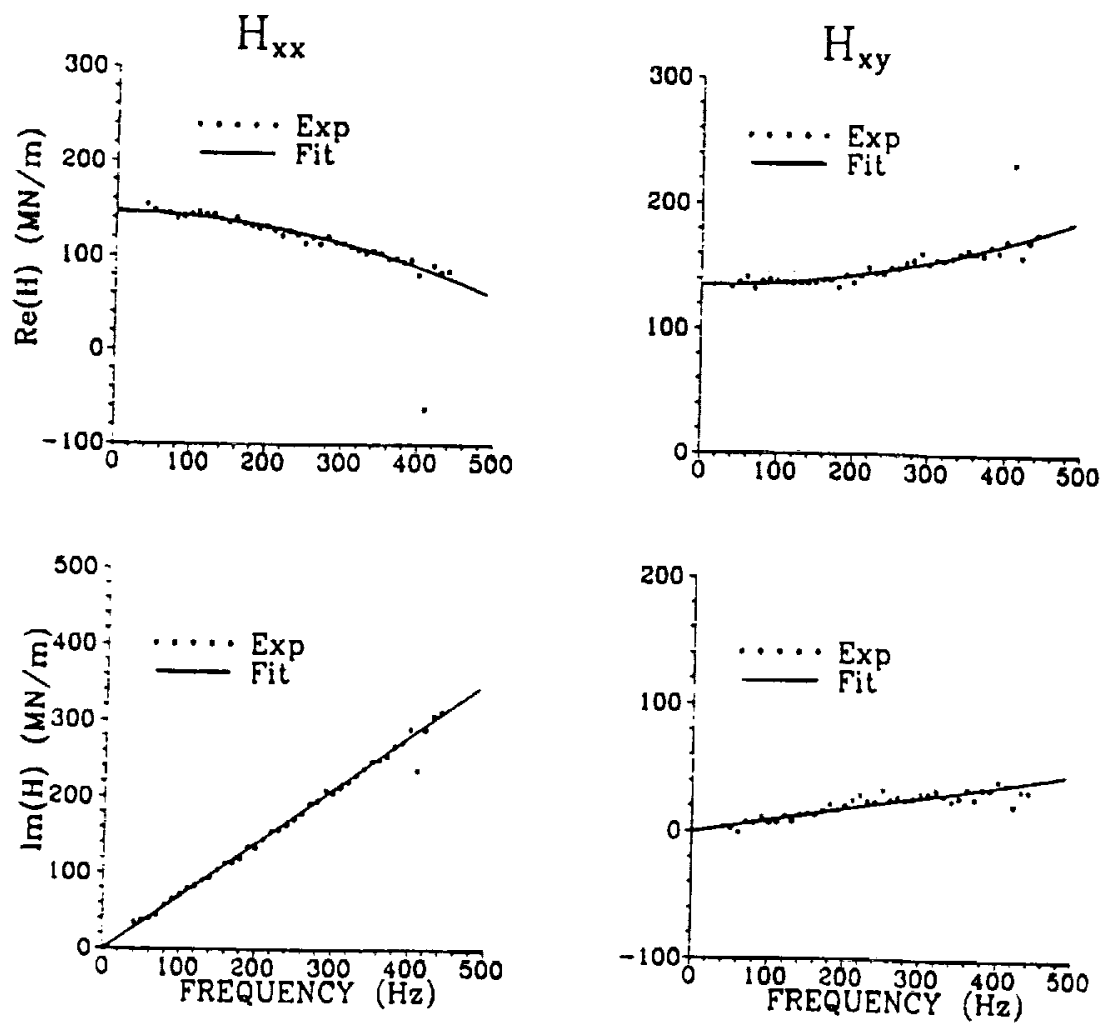
Figure 6 Real and imaginary parts of $\mathrm{Hxx}$ and Hxy for $\omega=24600 \mathrm{rpm}$, zero eccentricity, and
$6.9 \mathrm{Mpa}(1000 \mathrm{psi}$ ) supply pressure 

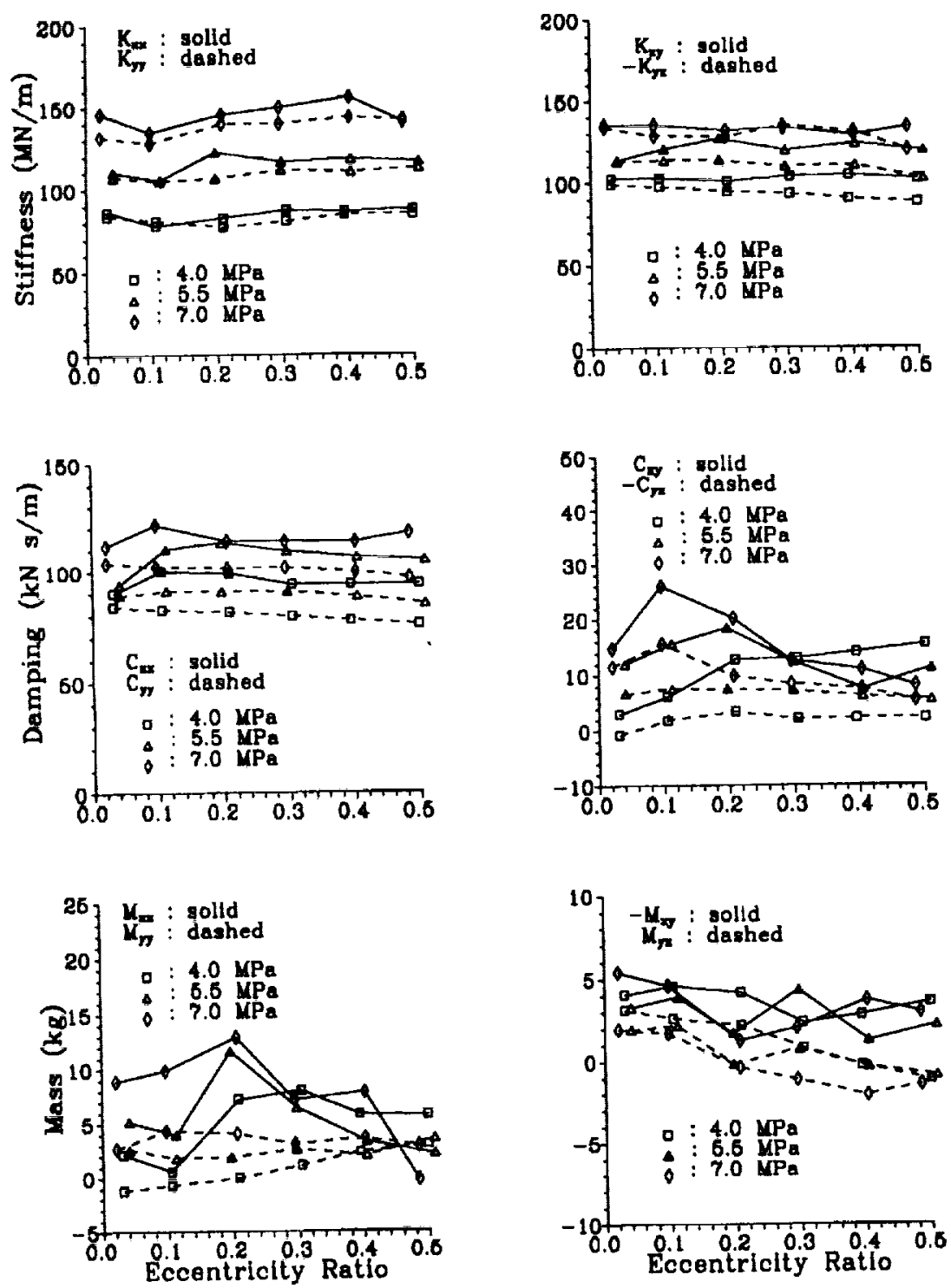

Figure 7 Stiffness, damping, and added-mass coefficients versus eccentricity ratio at $24600 \mathrm{rpm}$ for three supply pressures 
Recall from Eq.(6) that $K_{x x}$ and $M_{x x}$ come from the real part of $H_{x x}$, and $C_{x x}$ is oblained from the imaginary part of $\mathrm{H}_{x x}$, etc. Figure 7 illustrates the rotordynamic coefficients versus eccentricity ratio for a running speed of $24,600 \mathrm{rpm}$, a supply temperature of $54.4^{\circ} \mathrm{C}\left(130^{\circ} \mathrm{F}\right)$, and a range of supply pressures. The rotordynamic coefficients are seen to be generally insensitive to eccentricity ratio. Recall from figure 4 that the bearing is loaded toward the center of a recess, and the bearing is not symmetric. Hence, the direcl coefficients (e.g. $M_{x x}$ and $M_{y y}$ ) are not necessarily cqual at zero eccentricity. Note the large value for direct and crosscoupled mass coefficients which arise because of the elevated Reynolds number.

Figure 8 illustrates whirl-frequency-ratio $\mathrm{f}_{\omega}$ versus eccentricity ratio for three supply pressures at $24,600 \mathrm{rpm}$. The whirl-frequency ratio definition developed by San Andres (1991b) was used in these plots and depends on all the rotordynamic coefficients. Although not illustrated, $\mathbf{f}_{\omega}$ increases slightly with decreasing running speed. In the absence of other rotordynamic forces, the onset speed of inslability of a flexible rotor supported by plain journal bearings is approximately equal to the first critical specd divided by the whirl-frequency ratio, Lund (1966). Unfortunately, these test results show that $\mathrm{f}_{\omega} \cong 0.5$ for the hydrostatic bearings which is no better than a plain journal bearing. Constaninescu (1969) predicts this outcome for hybrid gas bearings.

\section{Uncertainty Analysis}

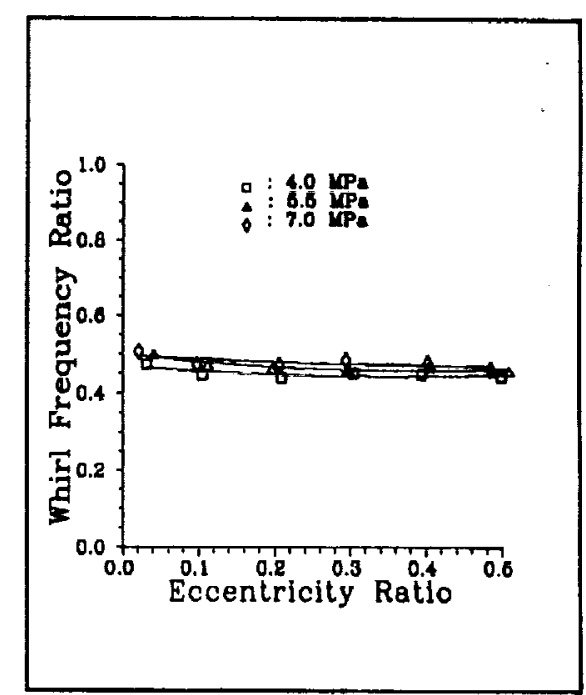

Figure 8 Whirl-frequency ratio versus eccentricity ratio for three supply pressures

A "dry-shake" test (one in which the bearing fluid film consists only of air at atmospheric pressure) was conducted to examine the magnitude of the stiffness and damping imposed on the stator by the cable, stinger, and other attachments. These values are negligible compared to the stiffness and damping of all bearings tested so far.

Table 3 contains estimates of the upper limit bias errors $B_{\text {Rss }}$ the precision indices $S_{\text {Rss }}$ and the absolute uncertainties $U_{\text {RSS }}$ of the coefficients for the test case of Figure 6 . These are obtained by calculating bias and precision errors for each element of the force and displacement matrices of Eq.(7) then numerically propagating these errors through the functional relationship between the elements and the resulting coefficients. The method used conforms to the ANSI/ASME standard on Measurement Uncertainty (1986). The coefficients fall within VALUE $+/ \cdot \mathbf{U}_{\mathrm{Rss}}$ for $95 \%$ coverage.

Table 3. Measurement Uncertainties for $\omega=24600 \mathrm{rpm}$, zero eccentricity, and 6.9 MPa (1000 psi).

$\begin{array}{llllll}\text { COEFFICIENT } & \text { VALUE } & \text { B }_{\mathrm{kSS}} & \mathbf{S}_{\mathrm{RGS}} & \mathrm{U}_{\mathrm{RSS}} & \mathrm{UNITS} \\ \mathrm{K}_{\mathrm{XX}} & 146 & 2.82 & 1.82 & 4.60 & \mathrm{MN} / \mathrm{m} \\ \mathrm{K}_{\mathrm{XY}} & 136 & 2.21 & 1.34 & 3.47 & \mathrm{MN} / \mathrm{m} \\ \mathrm{K}_{\mathrm{YX}} & -133 & 2.11 & 1.86 & 4.27 & \mathrm{MN} / \mathrm{m} \\ \mathrm{K}_{\mathrm{YY}} & 132 & 2.46 & 1.30 & 3.59 & \mathrm{MN} / \mathrm{m} \\ \mathrm{C}_{\mathrm{XX}} & 112 & 2.26 & 0.74 & 2.71 & \mathrm{kN} / \mathrm{m} \\ \mathrm{C}_{\mathrm{XY}} & 14.4 & 2.60 & 1.42 & 3.85 & \mathrm{kN} / \mathrm{m} \\ \mathrm{C}_{\mathrm{YX}} & -11.3 & 2.39 & 0.69 & 2.76 & \mathrm{kN} / \mathrm{m} \\ \mathrm{C}_{\mathrm{YY}} & 105 & 2.16 & 1.54 & 3.77 & \mathrm{kN} / \mathrm{m} \\ \mathrm{M}_{\mathrm{XX}} & 8.8 & 1.06 & 0.99 & 2.24 & \mathrm{~kg} \\ \mathrm{M}_{\mathbf{X Y}} & -5.1 & 0.50 & 0.79 & 1.66 & \mathrm{~kg} \\ \mathrm{M}_{\mathrm{YX}} & 2.2 & 0.44 & 1.00 & 2.04 & \mathrm{~kg} \\ \mathrm{M}_{\mathbf{Y Y}} & 2.9 & 1.06 & 0.59 & 1.58 & \mathrm{~kg}\end{array}$




\section{Summary, Conclusions, and Comments}

The results and discussions included here present and explain the design of a new test system for hybrid (combined hydrostatic and hydrodynamic) bearings. The tester can measure static parameters including pressures, flowrate, temperatures, drag torque, etc plus a full complement of force/displacement rotordynamic coefficients. The test system expedites rapid and flexible testing of fluid-film bearings. It combines proven design elements of earlier experimenters and state-of-the-art excitation and identification techniques to deliver high-quality data.

Space limitations have forced us to present only a very limited selection of the data which have been developed for a single "generic" bearing. Tests have been completed for approximately 30 bearings as of 1 August 1992.

As noted in the introduction, this test program aims to produce test data to help in developing and validating predictions which have been under concurrent development by San Andres (1990a, 1990b). San Andres uses a 2-D, bulk-flow Navier-Stokes model for flow in the bearing land, a compressible flow continuity requirement for the recess, a discharge-coefficient model for the orifice, and concentrated pressure drops for flow leaving the recess and entering the lands. The analysis applies for rectangular recesses and radial flow injection. Comparisons between measurements and predictions are generally good for rectangular-recess bearings and are presently being prepared for publication.

A central question involved in the development of the present apparatus concemed the required excitation device. Specifically, should impulse devices or shakers be employed? Impulse excitation is a standard approach for modal identification, Ewins (1986), and was pioneered by Nordmann for bearing parameter identification and subsequently for annular seals, Nordmann and Massman (1984). Hydraulic shakers were first used for parameter identification of annular seals by lino and Kaneko (1980).

Price is a central advantage of impulse devices over hydraulic shakers. The impulse "guns" which were initially purchased for this project cost less than one tenth the eventual cost of the hydraulic shakers. The decision to shift from impulse to shaker excitation, despite financial considerations, involved the quality and volume of data to be acquired. The hybrid bearings were extremely noisy. Pressure pulsations in their recesses generated unwanted relative bearing-rotor amplitudes of the same magnitude as that created by external excitation. As detailed by Rouvas et al. (1992), impulse excitation can be made to work, but only with many repetitions and averaging in the time domain. However, the FRF data developed by Rouvas et al. with impulse excitation never approaches the high quality shown in figure 6, despite averaging over 200 separate impulse excitations.

An additional practical problem with impulse excitation concerned tip selection for the impulse guns. Soft tips were required to deliver the required low-frequency force excitation, but they would not have survived testing a bearing over a large test matrix with 200-plus excitations per data point. A parallel identification concern involved the comparatively large peak rotor/stator amplitudes developed by impulse excitation which were necessary to give adequate amplitudes at discrete frequencies.

Having acquired and installed the hydraulic shakers, the nature of the excitation and identification procedures remained to be resolved. Pseudo-random excitation is used because it is fast, has no leakage in the analysis. The spectrum is shaped to only excite frequencies in the range of interest with energy only at each DFT analyzed spectral line, and only a few averages are needed due to its low crest factor and good signal-to-noise ratio (Herlufsen, 1985). This excitation technique, along with identification procedures as outlined by Bendat and Piersol (1986) and extended by Rouvas and Childs $(1992)^{4}$ eventually achieved the high-quality FRF's of figure 6.

The test results developed here show one principal limitation to the planned use of hybrid bearings in cryogenic turbopumps, specifically, a whirl-frequency ratio near 0.5 . With this whirlfrequency ratio, running speeds above twice the rotor's first critical speed are likely to yield unstable motion. Hence, recent developments within this program have considered the following options for improving rotordynamic stability by reducing $\mathrm{f}_{\omega}$ :

\footnotetext{
${ }^{4}$ See Appendix A
} 
(a) Directed injection against rotation. Tondl (1967) initially proposed injecting the fluid against rotor rotation as compared to the radial injection of figure 4.

(b) Roughened Stator. Von Pragenau (1982) initially proposed roughened stators for annular seals to yield, "damper seals."

Both of these approaches acl to reduce the average langential velocity within the bearing. Favorable tests (reduced $f_{\omega}$ ) have been completed for both types of improved bearing configurations and will be
reported shortly.

The emphasis of this work has been on the application of hybrid bearings to cryogenic turbopumps. However, they present obvious alternatives as product-lubricated bearings for commercial pumps. Katayama and Okada (1992) have recently reported the results of a 6-year development program at Tokyo Gas Co. implementing hybrid bearings into vertical liquified-natural-gas pumps.

As noted by Kurtin et al. (1991), two practical problems have been encountered which might restrict the applications of hybrid bearings to commercial pumps. First, considerable cavitation erosion has been experienced in the divergent section downstream of the orifice in Figure 5 after a comparatively short test time ( $\approx 4 \mathrm{hrs})$. The eroded part is made from 17-4PH stainless steel with a high yield strength. Tests of a modified bearing with the orifice exit flush to the recess ${ }^{5}$ showed no cavitation damage on the exil orifice surface but some roughening of the rotor. Given that the recess pressure is on the order of $3.5 \mathrm{MPa}(500 \mathrm{psi})$, this damage could be resulting from air bubbles coming out of solution in the water versus an actual phase change of the water. Long-term testing to investigate potential cavitation fluid which will actualed before these bearings are selected for commercial pumps. Tests with the product viewpoint will actually be used are advisable, since almost any fluid will be kinder from a cavitation The second probketdyne personnel report zero damage with liquid hydrogen.

originally used a 10 -micron concerns damage to the bearing due to fluid-borne debris. Our flow loop stream. Particles entering the bearing which was inadequate in removing particles from the flow circumferential damage grooves around would lodge at the comers of the recesses and then create eliminated the problem. None the less, the bronze stators. Switching to a 10-micron absolute filter this bearing type.

${ }^{5}$ The diverging transition section from the orifice exit to the recess is eliminated. 


\section{References}

Bendat J. S. and Piersol A. G. (1986), Random Data Analysis and Measurement Techniques, 2nd Edition, Wiley Interscience.

Constantinescu, V. N. (1969), Gas Lubrication, ASME, New York.

Ewins, D. J. (1986), Modal Testing: Theory and Practice, Briel \& Kjær.

Glienicke, J. (1966-67), "Experimental Investigation of the Stiffness and Damping Coefficients of Turbine Bearing and Their Application to Instability Prediction," Proc. Mech. Engrs., Vol. 181 (pl 3B).

lino, T. and Kaneko, H. (1980), "Hydraulic Forces Caused by Annular Pressure Seals in Centrifugal Pumps," proceedings of the 5th Rotordynamic Instability Workshop, Texas A\&M University, pp. 213225.

Herlufsen, H. (1985) "Digital Signal Analysis using Digital Filters and FFT Techniques", Selected reprints from "Technical Review", Brüel \& Kjaer, pp.199-252.

Kanki, H. and Kawakami, T. (1984), "Experimental Study on the Dynamic Characteristics of Pump Annular Seals," Vibrations in Rotating Machinery, proceedings of the 3rd IMechE International Conference on Vibrations in Rotating Machinery, York, England, pp. 159-166.

Katayama, T. and Okada, A. (1992), "Liquified Natural Gas Pump with Hydrostatic Journal Bearings", proceedings of the 9th International Pump Users Symposium, Texas A\&M University, pp. 39-50.

Kurtin, K., Childs D., San Andres L., and Hale K. (1991), "Experimental Versus Theoretical Characteristics of a High-Speed Hybrid (Combination Hydrostatic and Hydrodynamic) Bearing," accepted for publication in ASME Trans., Journal of Tribology.

Lund, J. (1966), "Self-Excited, Stationary Whirl Orbits of a Journal in a Sleeve Bearing," Ph.D. Thesis, Renselaer Polytechnic Instilute, Troy, N.Y.

Measurement Uncertainty, ANSI/ASME PTC 19.1-1985 Part 1, 1986 (reaffirmed 1991).

Mitchell, L. and Elliott, K. (1984), "How To Design Stingers for Vibration Testing of Structures" April edition of the Sound and Vibration magazine, pp. 14-18.

Nordmann R., and Massman, H. (1984), "Identification of Dynamic Coefficients of Annular Turbulent Seals," Rotordynamic Instability Problems in High-Performance Turbomachinery - 1984, NASA CP2338, Proceedings of a Workshop held at Texas A\&M University, pp. 295-311.

Rouvas, C. and Childs, D. (1992), "A Parameter Identification Method for the Rotordynamic Coefficients of a High Reynolds Number Hydrostatic Bearing," accepted for publication in the ASME Journal of Vibration and Acoustics.

Rouvas, C., Murphy, B. and Hale K. (1992), "Bearing Parameter Identification Using Power Spectral Density Methods," proceedings of the Fifth International Conference of Vibrations in Rotating Machinery, Bath, England, pp. 297-303.

San Andres, L. (1991b), "Effect of Eccentricity on the Force Response of a Hybrid Bearing," Tribology Transat:tions, Vol. 34, No. 4, pp.537-544. 
San Andres, L. (1990a), "Approximale Analysis of Turbulent Hybrid Bearings. Static and Dynamic Performance for Centered Operation," ASME Journal of Tribology, Vol. 112, pp. 692-698. San Andres, L. (1990b), "Turbulent Hybrid Bearings with Fluid Ineria Effects," ASME Journal of
Tribology, Vol 112, pp. 669-707.

Scharrer, J., Tellier, J., and Hibbs, R. (1991a), "A Sludy of the Transient Performance of Hydrostatic Journal Bearings. Part I: Test Apparatus and Facility," STLE Preprint 91-TC-3B-1, presented at the STLE/ASME Tribology Conference, St. Louis, Missouri.

Scharrer, J., Tellier, J., and Hibbs, R. (1992b), "A Study of the Transient Performance of Hydrostatic Journal Bearings. Part II: Experimental Results," STLE Preprint 91-TC-3B-2, presented at the STLE/ASME Tribology Conference, St. Louis, Missouri.

Tonnesen, J. and Hansen, P. (1982), "Some Experiments on the Steady State Characteristics of a Cylindrical Fluid Film Bearing Considering Thermal Effects," J. Lub. Tech. Trans. ASME, Vol. 103, pp.
107-114.

Tondl, A. (1967), "Bearings with a Tangential Gas Supply," University of Southampton, Department of Mechanical Engineering, Gas Bearing Symposium, United Kingdom, paper no. 4.

von Pragenau, G. (1982), "Damping Seals for Turbomachinery," NASA Technical Paper 1987. 


\section{Appendix A. Spectral-Density-Averaging for Rotordynamic-Coefficient Identification}

Spectral density averaging techniques are used to obtain the frequency-response functions (FRF) of Eq.(7), which defines a multi-inpul multi-output (MIMO) system. The inputs are $D_{x x}, D_{x y}, D_{y x}$, and $D_{y y}$, and the outputs are $F_{x x}-M A_{x x}, F_{x y}-M A_{x y}, F_{y x}-M A_{y x}$ and $F_{y y}-M A_{y y}$

Before calculating the FRF for this MIMO system, first consider the best solution for the FRF of a single-inpul single-output (SISO) systcm. A SISO system with a clean input $a$ and a noise contaminated output $b$ will be examined. According to Bendat and Peirsol, (1986) an unbiased estimate $H$, of the FRF for this type of SISO system is given by,

$$
H=\frac{G_{a b}}{G_{a a}}
$$

with $G_{.}$being the cross spectral density and $G_{a}$ the auto spectral density. For discrete data, (which we have) an FFT algorithm is used to calculate the Discrete Fourier Transforms (DFT's) of Eq.(A.1). In particular, the spectral densities are calculated by,

$$
G_{a,}=\frac{2}{n_{d} N \Delta t} \sum_{i=1}^{n_{d}} \Lambda_{i}^{*}(\omega) P_{i}(\omega)
$$

where $n_{d}$ is the number of statistically independent blocks of data, $N$ is the number of data points in each data block, $\Delta$ is the time increment between sampling of each data point, $A^{*}(\omega)=$ the complex conjugate of $\mathscr{T}\{(t)\}$ and $P(\omega)=\mathscr{T}\{p(t)\}(\mathcal{F}$ is used to represent the DFT here).

We wish to apply the unbiased estimator for the SISO system described above to the MIMO system of Eq. (7). First, recall that we have 32 statistically independent blocks of data $\left(n_{d}=32\right)$, each block containing $1024(N=1024)$ data points for each of the dynamic loads, accelerations, and relative motions whose $\mathcal{S}$ appear in Eq.(7). Next, we identify each independent dynamic load of Eq. $(T)\left(F_{x x}\right.$ and $\left.F_{y y}\right)$ as a clean input $a$, and each of the resulting elements of the force and displacement matrices as noise contaminated outputs b. Eq.(A.1) is then applied separately to each individual element of the force and displacement matrices, yielding an unbiased estimate for each input and output element contained in these matrices. The resulting equation,

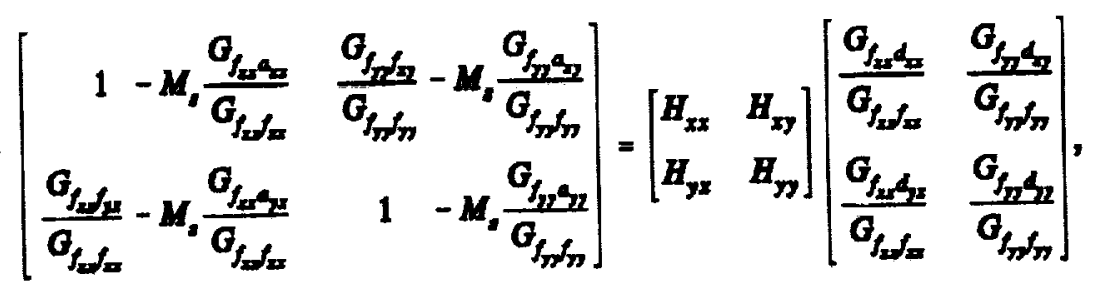

yields improved estimates for the FRF when solved.

Once Eq.(A.3) is solved, the rotordynamic coefficients are extracted from the FRF definitions of Eqs.(6) by performing a least-squares curve fit on the real and imaginary parts of each element of the FRF matrix. Plots of typical real and imaginary parts for Hxx are shown in Fig. 6. The stiffness, damping, and added-mass coefficients of Eqs. (1) and (3) have now been identified. A more detailed discussion is provided by Rouvas and Childs (1992). 


\section{Lists of Figures}

1. Bearing-test-apparatus layout

2. End view of a test bearing

3. Side-view of a lest bearing showing axial-tensioning cables

4. Test bearing

5. Orifice and recess detail

6. Real and imaginary parts of $\mathrm{H}_{x x}$ and $\mathrm{H}_{x y}$ for $\omega=24,600 \mathrm{rpm}$, zero eccentricity, and $6.90 \mathrm{Mpa}$ (1000 psi) supply pressure

7. Stiffness, Damping, and Added-mass coefficients versus eccentricity ratio at $24600 \mathrm{rpm}$ for three supply pressures

8. Whirl-frequency ratio versus eccentricity ratio at $24600 \mathrm{rpm}$ for three supply pressures

\section{Lists of Tables}

1. Test-bearing physical parameters (Refer to figure 4 for dimension definition).

2. Mnemonic definitions for measurements in figure 4 .

3. Measurement Uncertainties for $\omega=24600 \mathrm{rpm}$, zero eccentricity, and $6.90 \mathrm{MPa}$ (1000

psi) supply pressure 


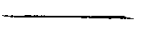

